\title{
Effect of pH, Temperature and Time Combinations on Yield and Degree of Esterification of Mango Peel Pectin: A Box-Behnken Design Based Statistical Modelling
}

\author{
S. Sangheetha*, D. C. K. Illeperuma ${ }^{1}$, A. N. Navaratne ${ }^{2}$ and C. Jayasinghe ${ }^{3}$ \\ Department of Food Technology \\ University College of Jaffna \\ Jaffna \\ Sri Lanka
}

\begin{abstract}
A 3-factor-3-level Box-Behnken design was employed to determine the effect of conditions: $\mathrm{pH}$, temperature and time on yield and degree of esterification (DE) of mango peel pectin obtained using acid extraction method. Fifteen experimental runs with different combinations of $p H\left(1.3,2.5\right.$ and 3.7), temperature $\left(60,75\right.$ and $\left.90{ }^{\circ} \mathrm{C}\right)$ and time $(45,90$ and $135 \mathrm{~min}$ ) were performed on mango peel collected from fruit processing industry. Acid extraction method was used to extract pectin. Yield and the DE of mango peel pectin varied from 6.1 to $16.3 \%$ (dry weight basis) and 45.5 to $87.5 \%$, respectively. Interactive effects of $p H$, temperature and time on the $D E$ were significant at $P<0.050$. The empirical quadratic second degree polynomial model developed for $D E$ in the study was significant $(P=0.000)$ and well fitted to all experimental data with $R^{2}$ of 99.48 . The study highlighted that mango peel from fruit processing industry can be used to produce high methoxyl (DE $>50 \%$ ) or low methoxyl pectin $(D E<50 \%)$ by controlling conditions during extraction and the model could be used to predict the DE of mango peel pectin for given conditions.
\end{abstract}

Keywords: Box-Behnken design, Degree of esterification, Fruit industry waste, High and low methoxyl pectins, Mango peel

\section{INTRODUCTION}

Pectin is a polysaccharide of galacturonic acids with branches of neutral sugars such as Lrhamnose, L-arabinose and D-galactose (Wai et al., 2010). Galacturonic acids in pectin are methyl esterified to various extents (Wang et al., 2017). The ratio of esterified galacturonic acid units to total galacturonic acids determines the degree of esterification (DE) (Flutto, 2003). Based on the DE, pectin is classified as "High methoxyl (HM) pectin" (DE $>50 \%$ ) and "Low methoxyl (LM) pectin" (DE < 50 \%) (Ranganna, 1986; Thakur et al., 1997). The DE determines gelling properties, solubility, emulsion activities, emulsion stability and release effects of pectin in complex food matrices, thus plays a unique role in food manufacturing (Srivastava and Malviya, 2011; Müller-Maatsch et al., 2016). However, as pectin is a constituent in plant cell wall, its yield and the DE depend on the chemical composition of plant cells and structure of pectin. Furthermore, nature of raw material,

\footnotetext{
${ }^{1}$ Department of Food Science and Technology, Faculty of Agriculture, University of Peradeniya, Sri Lanka.

${ }^{2}$ Department of Chemistry, Faculty of Science, University of Peradeniya, Sri Lanka.

${ }^{3}$ Department of Food Science and Technology, Faculty of Livestock, Fisheries and Nutrition, Wayamba University of Sri Lanka, Sri Lanka.

*Corresponding author: ssangheetha06@gmail.com
} 
method and conditions such as $\mathrm{pH}$, temperature, time, ionic strength of solution, solid: solution ratio of extraction affect yield and the DE of pectin (Yeoh et al., 2008; Begum et al., 2017; Sandarani, 2017).

Mango fruit is composed of approximately $11-18 \%$ peel, $14-22 \%$ seed and the rest being flesh (Mitra et al., 2013). In Sri Lankan context, mango peel and seed account for $51 \%$ of total fruit waste discarded by the fruit processing industry (Wathsala et al., 2017). As mango peel contains nearly 12 - 18.5\% pectin (Koubala et al., 2008; Girma and Worku, 2016), investigation of mango peel for pectin extraction is useful. Different extraction conditions are used to obtain pectin from fruit peels (Begum et al., 2017; Sandarani, 2017). Therefore, it is important to identify appropriate extraction conditions to obtain maximum possible yield of pectin. Hence, this study was conducted to investigate the effect of extraction conditions namely $\mathrm{pH}$, temperature and time on yield and the $\mathrm{DE}$ of mango peel pectin and to optimize these conditions to extract maximum possible pectin by employing Response Surface Methodology (RSM).

\section{METHODOLOGY}

\section{Collection and preparation of materials}

Fresh mango peel was obtained from fruit processing plants at CBL Natural Foods (Pvt) Limited, Minuwangoda, Sri Lanka and Kist Processing Plant, Kilinochchi, Sri Lanka. Peels were transported to the laboratories within $2-3 \mathrm{~h}$, cleaned, sorted, washed twice in potable running water and left for $10 \mathrm{~min}$ for moisture draining. The peels were disintegrated into pieces of approximately $1 \mathrm{~cm}^{2}$ and dehydrated at $55-60{ }^{\circ} \mathrm{C}$ for $7-8 \mathrm{~h}$ in a dehydrator (TSM Products, D10 - 32609, United States). The dehydrated pieces were ground in a tabletop laboratory grinder (Jaipan, India) and sieved through a laboratory sieve set (Ailmill, India) to make powder with particle size of $0.425-0.850 \mathrm{~mm}$. Mango peel powder was packaged in metalized polyester bags and stored in air tight polypropylene containers at ambient conditions until further use.

All chemicals used in the study were analytical grade purchased from Merck Chemicals, India, VWR chemicals, USA and Sigma Aldrich, Germany. Ethanol (96\%, v/v) was procured from Lanka Sugar Company (Pvt) Limited for extraction of pectin.

\section{Experimental design}

A 3-factor-3-level Box-Behnken design of response surface methodology (RSM) was employed to design the experimental runs and investigate the effect of extraction conditions $(\mathrm{pH}$, temperature and time) on yield and the $\mathrm{DE}$ of pectin. Fifteen experimental runs were carried out in triplicate represented by center points (Table 1). The conditions used were; $\mathrm{pH}$ of 1.3, 2.5 and 3.7, temperature of 60,75 and $90{ }^{\circ} \mathrm{C}$ and time of 45,90 and 135 min which were selected based on previous studies on various fruit peels (Kratchanova et al., 2004; Kanmani et al., 2014; Müller-Maatsch et al., 2016). The experimental runs were conducted in a randomized order. 
Table 1. Box- Behnken Design of RSM employed for investigation on the effect of extraction conditions on yield and degree of esterification of pectin extracted from mango peel

\begin{tabular}{cccc}
\hline \multirow{2}{*}{ Run No } & \multicolumn{3}{c}{ Extraction conditions and levels } \\
\cline { 2 - 4 } & $\mathbf{p H}$ & Temperature $\left({ }^{\mathbf{0}} \mathbf{C}\right)$ & Time $(\mathbf{m i n})$ \\
\hline 1 & 1.3 & 60 & 90 \\
2 & 3.7 & 60 & 90 \\
3 & 1.3 & 90 & 90 \\
4 & 3.7 & 90 & 90 \\
5 & 1.3 & 75 & 45 \\
6 & 3.7 & 75 & 45 \\
7 & 1.3 & 75 & 135 \\
8 & 3.7 & 75 & 135 \\
9 & 2.5 & 60 & 45 \\
10 & 2.5 & 90 & 45 \\
11 & 2.5 & 60 & 135 \\
12 & 2.5 & 90 & 135 \\
13 & 2.5 & 75 & 90 \\
14 & 2.5 & 75 & 90 \\
15 & 2.5 & 75 & 90 \\
\hline
\end{tabular}

Run number was generated by Minitab 17 statistical software

\section{Extraction of pectin}

Pectin from mango peel powder was extracted according to the method described by Kratchanova et al. (2004). Approximately $10 \mathrm{~g}$ of mango peel powder was mixed with 300 $\mathrm{ml}$ of distilled water and $\mathrm{pH}$ was adjusted to required levels indicated in Table 1 using $1 \mathrm{M}$ hydrochloric acid. The suspension was left for 20 - $30 \mathrm{~min}$ with occasional stirring for equilibrium. The $\mathrm{pH}$ was re-adjusted as required. Sample containers were partially covered with watch glasses and heated at predetermined temperatures for respective times (Table 1) in a water bath (Labtech, LWB-306DS). Subsequently, the hot suspension was filtered through a muslin cloth and cooled to $4{ }^{\circ} \mathrm{C}$ in an ice bath. An equal volume of $96 \%(\mathrm{v} / \mathrm{v})$ ethanol was gradually added to the sample and slowly stirred for nearly $5 \mathrm{~min}$. The solution was then allowed to rest for $1 \mathrm{~h}$ and the coagulated pectin was separated by filtering through a muslin cloth. Another equal volume of ethanol was added to the filtrate and coagulated pectin was separated as above. The isolated pectin was washed 5 times with $96 \%(\mathrm{v} / \mathrm{v})$ ethanol, dried at $35{ }^{\circ} \mathrm{C}$ in an air convection incubator (Pol- Eko Aparatura - CLW 15, Poland) for overnight and weighed after cooled to ambient temperature. The dried sample was ground into fine powder and stored in airtight amber glass containers under ambient conditions until determination of the DE.

\section{Determination of yield}

The yield of pectin from mango peel was calculated by using the Equation 1. 
Yield $(\%)=\frac{W_{o} X 100}{W_{1}}$

where, $\mathrm{W}_{0}$ is the weight of dried pectin before grinding and packaging $(\mathrm{g})$ and $\mathrm{W}_{1}$ is the weight of dried mango peel powder used for extraction $(\mathrm{g})$.

\section{Determination of the DE}

According to Pasandide et al. (2015), the powdered sample ( $0.2 \mathrm{~g})$ was added into a conical flask containing $20 \mathrm{ml}$ of distilled water and $3 \mathrm{ml}$ of $96 \%$ ethanol and thoroughly dissolved using a vortex mixer at $3000 \mathrm{rpm}$ (Velp Scientifica - ZX3, USA). The solution containing few drops of phenolphthalein indicator was titrated against $0.1 \mathrm{M}$ standardized sodium hydroxide $\left(\mathrm{V}_{1}\right)$. Then, $10 \mathrm{ml}$ of standardized $0.1 \mathrm{M}$ sodium hydroxide was added slowly to the solution while occasional swirling of the flask. After leaving the flask aside for $15 \mathrm{~min}$, $10 \mathrm{ml}$ of standardized $0.1 \mathrm{M}$ hydrochloric acid was added and mixed well. The solution was titrated against $0.1 \mathrm{M}$ standardized sodium hydroxide $\left(\mathrm{V}_{2}\right)$ using phenolphthalein as the indicator. The DE was calculated using the Equation 2.

$\mathrm{DE}=\frac{\mathrm{V}_{2} \times 100}{\mathrm{~V}_{1}+\mathrm{V}_{2}}$

\section{Statistical analysis of experimental data}

DE was estimated in duplicate and the average was used for modelling. Design of experiment and all statistical analysis were executed in Minitab 17 (Minitab Inc., State College, PA, USA). Multiple regression analysis was performed to develop an empirical quadratic second degree polynomial model. Experimental data were analyzed to fit the second degree polynomial equation (Equation 3) generated by Minitab 17.

$Y=\beta_{0}+\beta_{1} X_{1}+\beta_{2} X_{2}+\beta_{3} X_{3}+\beta_{12} X_{1} X_{2}+\beta_{13} X_{1} X_{3}+\beta_{23} X_{2} X_{3}+\beta_{11} X_{1}^{2}+\beta_{22} X_{2}^{2}+\beta_{33} X_{3}^{2}$

where,

$\mathrm{Y}-\mathrm{DE}$

$\mathrm{X}_{1}, \mathrm{X}_{2}$ and $\mathrm{X}_{3}-\mathrm{pH}$, temperature and time

$\beta_{0}$ - Intercept coefficient

$\beta_{1}, \beta_{2}, \beta_{3}$ - Linear coefficient

$\beta_{12}, \beta_{13}, \beta_{23}-$ Quadratic coefficient

$\beta_{11}, \beta_{22}, \beta_{33}$ - Interaction coefficient

Analysis of variance (ANOVA) was used to determine the significance and accuracy of developed empirical quadratic second degree polynomial model and to analyze the effect of extraction conditions on DE of mango peel pectin. 


\section{RESULTS AND DISCUSSION}

\section{Yield of mango peel pectin}

The conditions namely $\mathrm{pH}$, temperature and time (combinations of 15 experimental runs) used for extracting pectin from mango peel affected the yield varied from 6.1 to $16.3 \%$ (dry weight basis).

Combination of $\mathrm{pH} 2.5,90{ }^{\circ} \mathrm{C}$ and 135 min resulted in the highest yield whereas $\mathrm{pH} 3.7,60$ ${ }^{\circ} \mathrm{C}$ and 90 min resulted in the lowest yield (Table 2).

Table 2. Yield of pectin extracted from mango peel under different combinations of extraction conditions using Box-Benkhen design

\begin{tabular}{ccccc}
\hline \multirow{2}{*}{$\begin{array}{c}\text { Run } \\
\text { No }\end{array}$} & pH & Temperature $\left({ }^{\mathbf{}} \mathbf{C}\right)$ & Time (min) & Yield (\%) \\
\cline { 2 - 5 } 1 & 1.3 & 60 & 90 & $11.5^{\mathrm{a}}$ \\
2 & 3.7 & 60 & 90 & $6.1^{\mathrm{b}}$ \\
3 & 1.3 & 90 & 90 & $11.8^{\mathrm{c}}$ \\
4 & 3.7 & 90 & 90 & $14.6^{\mathrm{d}}$ \\
5 & 1.3 & 75 & 45 & $12.7^{\mathrm{e}}$ \\
6 & 3.7 & 75 & 45 & $8.7^{\mathrm{f}}$ \\
7 & 1.3 & 75 & 135 & $13.3^{\mathrm{g}}$ \\
8 & 3.7 & 75 & 135 & $13.4^{\mathrm{h}}$ \\
9 & 2.5 & 60 & 45 & $8.4^{\mathrm{i}}$ \\
10 & 2.5 & 90 & 45 & $15.0^{\mathrm{j}}$ \\
11 & 2.5 & 60 & 135 & $9.8^{\mathrm{k}}$ \\
12 & 2.5 & 90 & 135 & $16.3^{1}$ \\
13 & 2.5 & 75 & 90 & $13.2^{\mathrm{m}}$ \\
14 & 2.5 & 75 & 90 & $14.3^{\mathrm{n}}$ \\
15 & 2.5 & 75 & 90 & $13.8^{\mathrm{o}}$ \\
\hline
\end{tabular}

Means in the same column that do not share the same letter are significantly different

Multiple regression analysis of experimental data revealed that $17.1 \%$ of pectin could be extracted at $\mathrm{pH} 3.38,90{ }^{\circ} \mathrm{C}$ for $135 \mathrm{~min}$. Pectin yield obtained in this study is in agreement with previous studies where $\mathrm{pH} 2.0,82{ }^{\circ} \mathrm{C}$ for 120 min resulted in $18.5 \%$ of pectin (Girma and Worku, 2016) and $\mathrm{pH} 1.5,85^{\circ} \mathrm{C}$ for 60 min resulted in $12.0 \%$ pectin (Koubala et al., 2008) from mango peel. Moreover, extraction at $\mathrm{pH} 2.0,100{ }^{\circ} \mathrm{C}$ for 60 min resulted in $21.7 \%$ pectin from alcohol insoluble residue of mango peel (Patel, 2017). Yields of pectin extracted from mango peel are comparable with the same obtained from other commercially used plant materials such as citrus peel, apple pomace and sugar beet which yielded $18-30,16.68$ and 16.2\%, respectively (Yapo et al., 2007; Liew et al., 2018; Wang et al., 2014). Thus, the present study revealed that fresh mango peel from processing industry could be successfully used for commercial scale pectin extraction in Sri Lanka. 


\section{The DE of mango peel pectin}

The presence of both HM pectin (DE $>50 \%)$ and LM pectin $(\mathrm{DE}<50 \%)$ in the extracted mango peel pectin was evident (Table 3). Previous studies reported the presence of only HM pectin with DE ranging between 53 and $79 \%$ in mango peel pectin and the need for further de-esterification to obtain LM pectin (Berardini et al., 2005; Sirisakulwat et al., 2010; Geerkins et al., 2015; Patel, 2017; Oleivera et al., 2018). Such variations in the DE of pectin may probably be attributable to the differences in mango variety, ripening stage and extraction conditions. Nonetheless, the present study clearly showed that LM pectin can also be produced from mango peel by proper adjustment of extraction conditions ( $\mathrm{pH}$, temperature and time) without de-esterifying HM pectin, which is an addition in cost.

Table 3. Degree of esterification of pectin extracted from mango peel under different extraction conditions using Box-Benkhen design

\begin{tabular}{ccccc}
\hline \multirow{2}{*}{$\begin{array}{c}\text { Run } \\
\text { No }\end{array}$} & pH & Temperature $\left({ }^{\mathbf{o}} \mathbf{C}\right)$ & Time (min) & DE (\%) \\
\hline 1 & 1.3 & 60 & 90 & $45.5^{\mathrm{o}}$ \\
2 & 3.7 & 60 & 90 & $87.5^{\mathrm{a}}$ \\
3 & 1.3 & 90 & 90 & $45.7^{\mathrm{n}}$ \\
4 & 3.7 & 90 & 90 & $75.0^{\mathrm{j}}$ \\
5 & 1.3 & 75 & 45 & $54.4^{1}$ \\
6 & 3.7 & 75 & 45 & $87.1^{\mathrm{b}}$ \\
7 & 1.3 & 75 & 135 & $51.9^{\mathrm{m}}$ \\
8 & 3.7 & 75 & 135 & $85.4^{\mathrm{c}}$ \\
9 & 2.5 & 60 & 45 & $83.3^{\mathrm{e}}$ \\
10 & 2.5 & 90 & 45 & $83.9^{\mathrm{d}}$ \\
11 & 2.5 & 60 & 135 & $81.8^{\mathrm{f}}$ \\
12 & 2.5 & 90 & 135 & $71.4^{\mathrm{k}}$ \\
13 & 2.5 & 75 & 90 & $76.9^{\mathrm{i}}$ \\
14 & 2.5 & 75 & 90 & $77.8^{\mathrm{h}}$ \\
15 & 2.5 & 75 & 90 & $78.8^{\mathrm{g}}$ \\
\hline
\end{tabular}

Means in the same column that do not share the same letter are significantly different

\section{Regression model for DE of mango peel pectin}

The empirical quadratic second degree polynomial model developed based on $\mathrm{pH}$, temperature and time is as follows;

$$
\begin{aligned}
\mathrm{DE}= & -86.3+70.07 \mathrm{pH}+1.977 \text { Temperature }-0.142 \text { Time }-8.665 \mathrm{pH} \times \mathrm{pH}-0.00912 \\
& \text { Temperature } \times \text { Temperature }+0.002140 \text { Time } \times \text { Time }-0.1708 \mathrm{pH} \times \text { Temperature } \\
& +0.0039 \mathrm{pH} \times \text { Time }-0.00405 \text { Temperature } \times \text { Time }
\end{aligned}
$$

$\mathrm{F}$ value (5.76) and $\mathrm{P}$-value $(P=0.000)$ of the model confirmed its significance and accuracy. Insignificant lack of fit $(P=0.152)$ denoted that the model adequately fitted to experimental data. Coefficient of determination $\left(R^{2}=99.48\right)$, adjusted $R^{2}(98.54)$, and predicted $R^{2}(92.41)$ 
were close to 1, which further ensured the fitness of the model with experimental data (Table 4). The value of $\mathrm{R}^{2}$ (99.48) indicated that $99.48 \%$ total variation by $\mathrm{pH}$, temperature and time can be explained by the model to predict $\mathrm{DE}$ with only $0.52 \%$ of total variation that could not be revealed. These findings confirmed that the model could be used to predict DE of mango peel pectin for given extraction condition.

Table 4. Analysis of variance of regressed model for effect of extraction conditions on degree of esterification of pectin extracted from mango peel

\begin{tabular}{lccccc}
\hline Source & $\begin{array}{c}\text { Contribution } \\
(\%)\end{array}$ & Adj SS & Adj MSS & F-Value & P-Value \\
\hline Model & 99.48 & 3207.65 & 356.41 & 106.12 & $\mathbf{0 . 0 0 0}$ \\
Linear & 76.07 & 2452.81 & 817.60 & 243.43 & $\mathbf{0 . 0 0 0}$ \\
pH & 72.94 & 2351.97 & 2351.97 & 700.27 & 0.000 \\
Temperature & 1.83 & 59.14 & 59.14 & 17.61 & 0.009 \\
Time & 1.29 & 41.71 & 41.71 & 12.42 & 0.017 \\
Square & 21.31 & 687.02 & 229.01 & 68.18 & $\mathbf{0 . 0 0 0}$ \\
pH*pH & 18.50 & 574.86 & 574.86 & 171.16 & 0.000 \\
Temperature* & 21.12 & 15.53 & 15.53 & 4.63 & 0.084 \\
Temperature & 2.15 & 69.36 & 69.36 & 20.65 & 0.006 \\
Time* Time & 2.10 & 67.82 & 22.61 & 6.73 & $\mathbf{0 . 0 3 3}$ \\
2-way interaction & 1.17 & 37.79 & 37.79 & 11.25 & 0.020 \\
pH* Temperature & 0.01 & 0.18 & 0.18 & 0.05 & 0.826 \\
pH*Time & 0.93 & 29.85 & 29.85 & 8.89 & 0.031 \\
Temperature* Time & 0.52 & 16.79 & 3.36 & & \\
Error & 0.47 & 15.05 & 5.02 & $\mathbf{5 . 7 6}$ & $\mathbf{0 . 1 5 2}$ \\
Lack-of-fit & 0.05 & 1.74 & 0.87 & & \\
Pure error & 100.00 & & & & \\
Total & 99.48 & & & & \\
$\mathrm{R}^{2}$ & 98.54 & & & & \\
$\mathrm{R}^{2}$ adjusted & 92.41 & Adj MSS - Adjusted mean sum square & & \\
$\mathrm{R}^{2}$ predicted & & & & & \\
Adj SS - Adjusted sum square & & & &
\end{tabular}

The effect of $\mathrm{pH}$, temperature and time on the DE

$\mathrm{pH}(P=0.000)$ and time $(P=0.030)$ exhibited significant main effects on the DE of mango peel pectin while temperature $(P=0.080)$ did not. Interactive effects, which included linear effect of $\mathrm{pH}(P=0.000)$, temperature $(P=0.009)$ and time $(P=0.017)$, cubic effect of $\mathrm{pH}$ $(P=0.000)$ and time $(P=0.006)$ and quadratic effects of $\mathrm{pH}$ - temperature $(P=0.020)$ and temperature - time $(P=0.031)$ on DE were significant. However, cubic effect of temperature $(P=0.084)$ and quadratic effect of $\mathrm{pH}$ - time $(P=0.826)$ did not show significant effect $(P=0.826)$ on DE of mango peel pectin. Similar findings were reported by other researchers for mango peel (Koubala et al., 2008; Faruque et al., 2016), durian peel (Wai et al., 2010) and banana peel (Emanga et al., 2008). The curvature in all 3D surface graphs (Figures 1, 2 and 3), demonstrated that the model carries quadratic effects of $\mathrm{pH}$, temperature and time on $\mathrm{DE}$ that were statistically significant at $\mathrm{P}<0.050$. Increase in DE was evident at higher level of $\mathrm{pH}$ and the highest was observed at upper left corner of the graph corresponds with the 
lowest ti

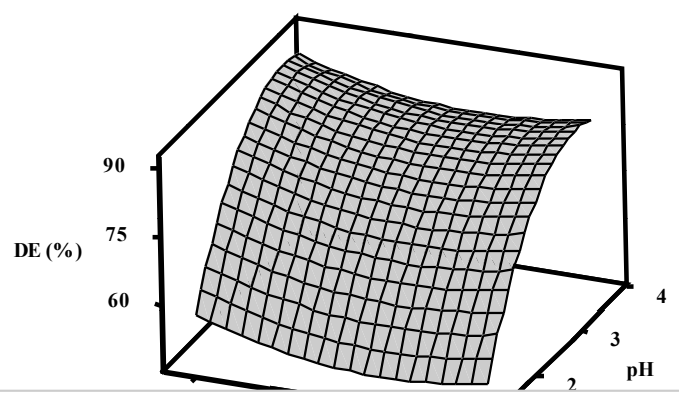

Surface Plot of DE (\%) vs pH, Temperature

Figure 1

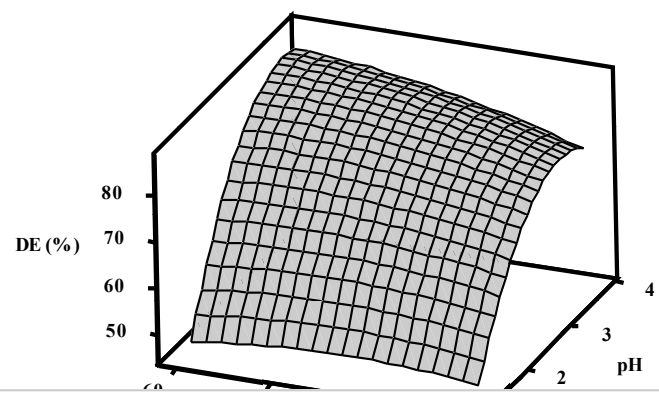

Surface Plot of DE (\%) vs Time, Temperature

Figure 2.

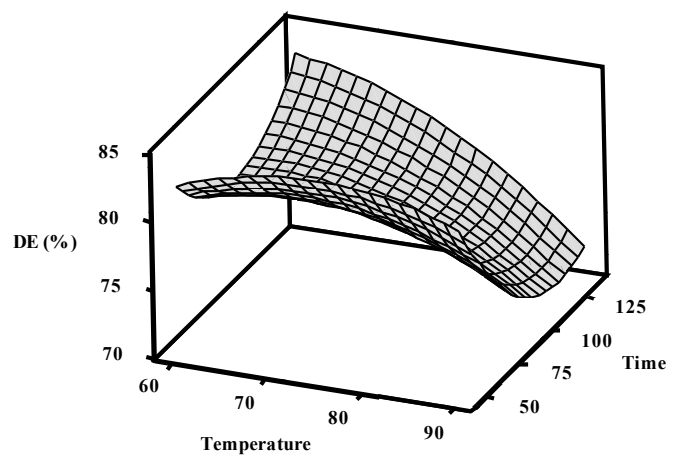

Figure 3. 


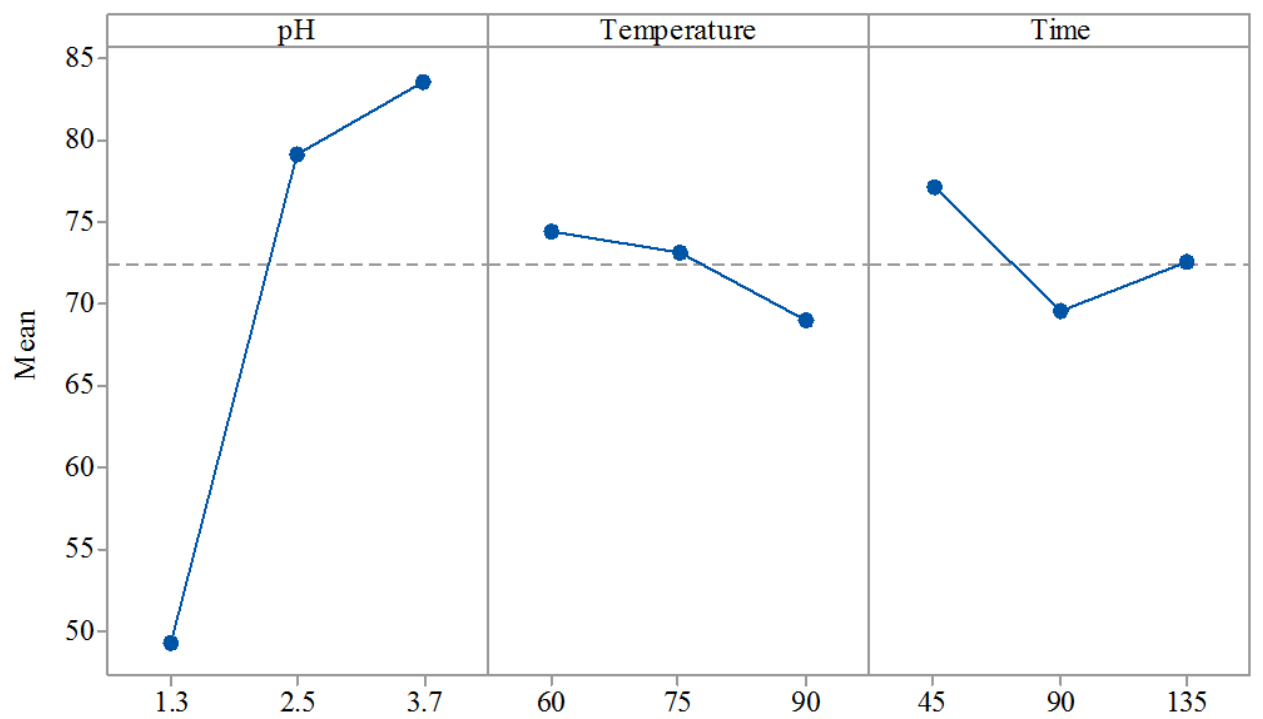

Figure 4. Main effect of $\mathrm{pH}$, temperature and time on degree of esterification of pectin from mango peel

Main effects of $\mathrm{pH}$, temperature and time on $\mathrm{DE}$ of mango peel pectin revealed direct impact of $\mathrm{pH}$ increments on DE (Figure 4). When the $\mathrm{pH}$ increases, inadequacy of $\mathrm{H}^{+}$ions to deesterify pectin during extraction was indicated by steep ascent in $\mathrm{DE}$ up to $\mathrm{pH} 2.5$ and moderate upsurge thereafter up to $\mathrm{pH} 3.7$. With the rise in temperature, as more thermal energy is available to hydrolyze the ester bonds, further de-esterification of pectin during extraction was evident in this study. Similar results were reported in previous studies for peels of citrus (Kanmani et al., 2014), mango (Sayah et al., 2014) and banana (Emanga et al., 2008). With increase in duration (time) of extraction, as the amount of thermal energy available to hydrolyze the ester bonds increases, de-esterification enhances, thereby reducing the DE of pectin (Adetunji et al., 2017). However, reduction in the DE was evident during extraction up to $90 \mathrm{~min}$ and an increase thereafter up to $135 \mathrm{~min}$. This may probably be due to the presence of other constituents such as carbohydrates, proteins and bioactive compounds in mango peels, which may possibly interfere with the extraction process.

\section{CONCLUSIONS}

The main and interactive effects of $\mathrm{pH}$, temperature and time significantly contribute to $\mathrm{DE}$ and yield of mango peel pectin. Mango peel could be a good commercial source for pectin production since it yielded $17.2 \%$ pectin that is comparable to other commercial sources such as apple pomace and sugar beet. The $\mathrm{pH}$ and time duration should be employed more carefully than temperature to obtain pectin with required DE since the effect of the former on $\mathrm{DE}$ is higher than that of the latter. The developed empirical quadratic second degree polynomial model can be used to predict the DE of mango peel pectin at commercial scale processing since the model was in good agreement with experimental data. Mango peel pectin with less than or more than $50 \% \mathrm{DE}$ could be obtained when $\mathrm{pH}$, temperature and time are manipulated according to the model. Hence, mango peel from fruit processing industries can be used as a single source to extract both HM and LM pectins, depending on their role in manufacturing of different foods whereas the commercial pectin resources used 
at the present give only high methoxyl pectin and require an additional de-esterification process step to produce low methoxyl pectin.

\section{ACKNOWLEDGEMENT}

The research grant of RG/2017/AG/2 by National Science Foundation, Sri Lanka is hereby gratefully acknowledged.

\section{REFERENCES}

Begum, R., Yusof, Y. A., Aziz, M. G. and Uddin, M. B. (2017). Screening of fruit wastes as pectin source: Journal of Environmental Science and Natural Resources. 10(1), 65-70.

Berardini, N., Fezer, R., Conrad, J., Beifuss, U., Carle, R., and Schieber, A. (2005). Screening of mango (Mangifera indica L.) cultivars for their contents of flavonol O- and xanthone C-glycosides, anthocyanins, and pectin: Journal of Agricultural and Food Chemistry. 53, 1563-1570.

Emanga, T. H., Ronkart, S. N., Robert, B. C. and Paquot, M. (2008). Characterization of pectins extracted from banana peels (Musa AAA) under different conditions using an experimental design: Food Chemistry. 108, 463-471.

Faruque, M. O., Kamrul, N., Begum, A. A., Mazumder, M. A. R., and Uddin, M. B. (2016). Effect of extraction methods on the characteristics of pectin from mango peel wastes: International Journal of Agricultural and Food Science. 6(2), 70-75.

Flutto, L. (2003). Pectin: properties and determination. pp. 4440-4449. In: B. Caballero, B., Trugo, L.C. and Finglas, P. M. (Ed.) Encyclopedia of Food Sciences and Nutrition. CA Academic Press, San Diego, California, United Sates.

Geerkens, C. H., Nagel, A., Just, K. M., Miller-Rostek, P., Kammerer, D. R., Schweiggert, R. M. and Carle, R. (2015). Mango pectin quality as influenced by cultivar, ripeness, peel particle size, blanching, drying, and irradiation: Food Hydrocolloids. 51, 241-251.

Girma, E. and Worku, T. (2016). Extraction and characterization of pectin from selected fruit peel waste: International Journal of Scientific and Research Publications. 6(2), 447-454.

Kanmani, P., Dhivya, E., Aravind, J. and Kumaresan, K. (2014). Extraction and analysis of pectin from citrus peels: augmenting the yield from Citrus limon using statistical experimental design: Iran Journal of Energy Environment. 5, 303-312.

Koubala, B. B., Kanscia, G., Mbomeb, L. I., Cre'peauc, M. J., Thibaultc, J. F. and Raletc, M. C. (2008). Effect of extraction conditions on some physicochemical characteristics of pectins from "Ame'liore'e"' and "Mango" mango peels: Food Hydrocolloids. 22, 1345-1351.

Kratchanova, M., Nikolova, M., Pavlova, E., Yanakieva, I. and Kussovski, V. (2010). Composition and properties of biologically active pectic polysaccharides from leek (Allium porrum L.): Journal of Science and Food Agriculture. 90(12), 2046-2050. 
Levigne S., Ralet M. C. and Thibault J. F. (2002). Characterization of pectins extracted from fresh sugar beet under different conditions using an experimental design: Carbohydrate Polymers. 49, 145-153.

Liew, S. Q., Ngoh, G. C., Yusoff, R. and Teoh, W. H. (2018). Acid and deep eutectic solvent (DES) extraction of pectin from pomelo (Citrus grandis (L.) Osbeck) peels: Biocatalysis and Agricultural Biotechnology. 13, 1-11.

Methacanon, P., Krongsin, J. and Gamonpilas, C. (2013). Pomelo (Citrus maxima) pectin: Effects of extraction parameters and its properties: Journal of Food Hydrocolloid. 35, 383391.

Mitra, S. K., Pathak, P. K., Devi, H. L. and Chakraborty, I. (2013). Utilization of seed and peel of mango: Acta Horticulture. 992, 593-596.

Müller-Maatsch, J., Bencivenni, M., Caligiani, A., Tedeschi, T., Bruggeman, G., Bosch, M., Petrusan, J., Van, D. B., Elst, K. and Sforza, S. (2016). Pectin content and composition from different food waste streams: Food chemistry. 201, 37-45.

Oliveira, A. do N., Paula, D. de A., De Oliveira, E. B., Saraiva, S., Paulo, S. and Ramos, A. (2018). Optimization of pectin extraction from Ubá mango peel through surface response methodology: International Journal of Biological Macromolecules. 113,395-402.

Pasandide, B., Khodaiyan, F., Zeinab, E. and Hosseini, M. S. S. (2017). Optimization of aqueous pectin extraction from Citrus medica peel: Carbohydrate Polymers. 178, 27-33.

Ranganna, S. (1986). Handbook of analysis and quality control for fruits and vegetables products. $2^{\text {nd }}$ Ed. Mc Graw Hill publishing Ltd, New Delhi, pp.33-43.

Sandarani, M. D. J. C. (2017). A Review: Different Extraction Techniques of Pectin: Journal of Pharmacognosy and Natural Products. 3(3), doi: 10.4172/2472-0992.1000143

Sayah, M. Y., Chabir, R., El Kandri, Y. R., Chahdi, F. O., Touzani, H. and Errachidi, F. (2014). Optimization of pectin extraction from steam distillated orange peels through an experimental factorial design: International Journal of Innovation and Applied Studies. 11, 1642-1649.

Sirisakulwat, S., Sruamsiri, P., Carle, R. and Neidhart, S. (2010). Resistance of industrial mango peel waste to pectin degradation prior to by-product drying: International Journal of Food Science and Technology. 45, 1647-1658.

Srivastava, P. and Malviya, R. (2011). Sources of pectin, extraction and its applications in pharmaceutical industry - An overview: Indian Journal of Natural Products and Resources. 2(1), 10-18.

Thakur, B. R. (1997). Chemistry and uses of pectin - A review: Critical Reviews in Food Science and Nutrition. 37, 47-73.

Wai, W. W., Alkari, A. F. M. and Easa, A. M. (2010). Effect of extraction conditions on yield and degree of esterification of durian rind pectin: An experimental design: Food and bio product processing. $88,209-214$. 
Wang, W., Wu, X., Chantapakul, T., Wang, D., Zhang, S., Maa, X., Ding, T., Ye, X. and Liu, D. (2017). Acoustic cavitation assisted extraction of pectin from waste grapefruit peels: A green two-stage approach and its general mechanism: Food Research International. 102, $101-110$.

Wathsala, L. H. A. G., Maheshika, M. D. I., Illeperuma, C., Nawarathna, A., Sukirtha, S. and Jayasinghe, C. V. L. (2017). Possibility of incorporation the pineapple pulp waste in food industry as a solution to Sri Lankan fruit processing by products: Proceedings of $73^{\text {rd }}$ Annual Conference of Sri Lankan Association for Advancement of Science. 118.

Yapo, B. M., Robert, C., Etienne, I., Wathelet, B. and Paquot, M. (2007). Effect of extraction conditions on the yield, purity and surface properties of sugar beet pulp pectin: Food Chemistry. 100(4), 1356-1364.

Yeoh, S., Shi, J., Langrish, T. A. G. (2008). Comparisons between different techniques for water-based extraction of pectin from orange peels: Journal of Desalination. 218(3), 229237.

Wang, X., Chen, Q. and Lü, X. (2014). Pectin extracted from apple pomace and citrus peel by subcritical water: Food Hydrocolloids. 38, 129-137. 